\title{
Repression and activation by multiprotein complexes that alter chromatin structure
}

\author{
Robert E. Kingston, ${ }^{1}$ Christopher A. Bunker, and Anthony N. Imbalzano \\ Department of Molecular Biology, Massachusetts General Hospital, Boston, Massachusetts, 02114 USA, and Department of \\ Genetics, Harvard Medical School, Boston, Massachusetts 02115
}

The notion that chromatin structure might play an essential role in regulating gene expression was referred to in print as "the last refuge of scoundrels" as recently as 1986 (Brent 1986). Apparently, this view was widely held judging from the placement and time allotted to chromatin talks at transcription meetings. In the past decade, however, numerous structural, genetic, and biochemical studies have merged to present powerful arguments for the importance of chromatin structure in regulation. Chromatin structure on promoters has been shown to be dynamic, in that it can be altered during regulatory events in the absence of DNA replication (Schmid et al. 1992; for review, see Felsenfeld 1992). These data have been the subject of numerous recent reviews (Winston and Carlson 1992; Adams and Workman 1993; Becker 1994; Paranjape et al. 1994; Wolffe 1994; Orlando and Paro 1995; Roth 1995; Simon 1995). Here, we discuss the genetic and biochemical data that support the existence of multiprotein complexes whose primary function is to mediate changes in chromatin structure.

Over the past 50 years genetic studies in Saccharomyces cerevisiae and Drosophila melanogaster have identified numerous genes that are required for activation and repression. It now appears that some of these genes encode components of large complexes that interact directly with nucleosomes either to stabilize or destabilize nucleosome structure, leading to either repression or activation. The ongoing characterization of these complexes offers the hope that in the near future a direct mechanistic pathway leading from a promoter-bound activator or repressor to a regulated alteration in chromatin structure can be elucidated.

The characterization of these complexes is necessary to understand general transcriptional regulatory mechanisms and is likely to be particularly important in characterizing the mechanisms that regulate expression of genes during developmental processes. Many of the proteins that constitute the complexes discussed below were identified originally in genetic screens for mutations that affect processes such as appropriate segmentation in Drosophila, mating-type switching in yeast, and neoplasia in mammals (e.g., Stern et al. 1984; Ken-

\footnotetext{
${ }^{1}$ Corresponding author.
}

nison and Tamkun 1988; Haupt et al. 1991; van Lohuizen et al. 199la). It has long been appreciated that changes in chromatin structure, as visualized by nuclease hypersensitive sites, accompany induction of tissue-specific genes during development and differentiation (Gross and Garrard 1988). The macromolecular complexes discussed below are likely to play an essential role in the maintenance of specifically altered chromatin states as cells differentiate during development.

\section{Regulated steps on chromatin templates}

To understand how these complexes might function, it is first necessary to consider the steps in transcriptional regulation that might be altered by chromatin structure. Activation of a promoter in chromatin will require, at a minimum, binding by transcriptional activators, formation of the general transcription factors into an active preinitiation complex, and efficient initiation and elongation by RNA polymerase. Nucleosomes, the primary component of chromatin structure, have been shown to inhibit each of these steps in vitro (Fig. 1), and binding of histone $\mathrm{H} 1$ and formation of higher order structures almost certainly enhances these inhibitory effects (Lorch et al. 1987; Kamakaka et al. 1993; for review, see Felsenfeld 1992; Adams and Workman 1993). Many of these steps occur permissively on naked templates but are strongly inhibited in chromatin. For example, most activators will bind to their site with an affinity of at least $10^{-9} \mathrm{M}$ on naked DNA. In contrast many activators bind with a $K_{\mathrm{d}}$ of $10^{-7} \mathrm{M}$ or higher on nucleosomal templates (for review, see Adams and Workman 1993). The general factors TBP, TFIIA, and TFIIB are able to recognize most TATA sequences on naked DNA with a $K_{\mathrm{d}}$ of $10^{-9}$ to $10^{-10} \mathrm{M}$ but are unable to bind at all to certain nucleosomal templates at concentrations as high as $10^{-6} \mathrm{M}(\mathrm{Im}$ balzano et al. 1994). Similarly, transcriptional elongation occurs efficiently on most naked templates, but formation of the template into nucleosomes significantly inhibits the elongation rate of RNA polymerase II (Izban and Luse 1992), apparently because the nucleosome must "step around" the transcribing polymerase (Studitsky et al. 1994, 1995). Activators might function by recruiting complexes that decrease the inhibitory nature of chromatin structure at each of these steps, whereas 


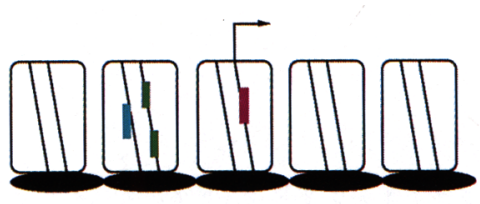

Initial factor binding

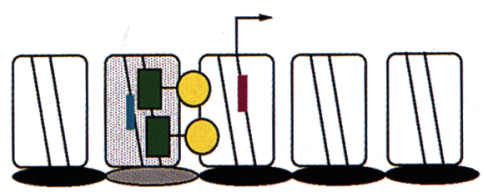

Enhancement of activator binding

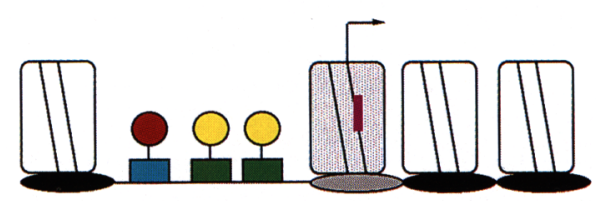

Formation of pre-initiation complex

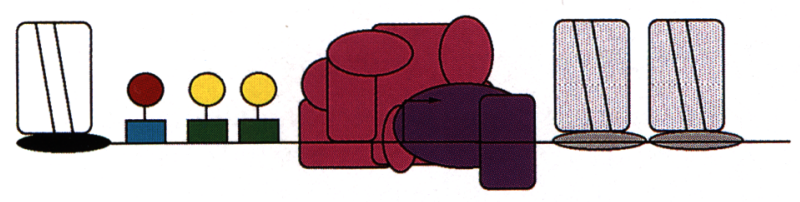

Promoter clearance and Elongation

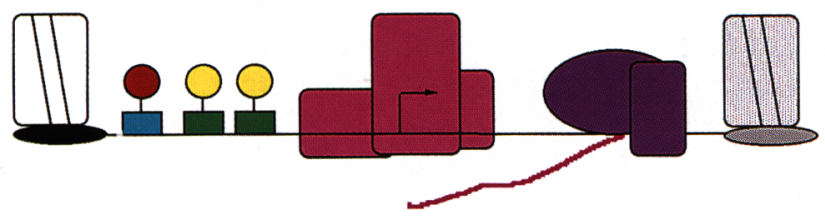

Figure 1. Steps in transcriptional activation that are inhibited by nucleosome formation. These steps are shown as occurring sequentially for clarity; it is likely that some of these steps occur in a concerted fashion in vivo.

repressors might recruit complexes that stabilize chromatin structure.

\section{Activation on chromatin templates}

By the early 1990s, genetic and biochemical studies on transcriptional activation suggested the existence of gene products that might be directly involved in modifying chromatin structure to achieve transcriptional activation. Mutations in the amino termini of histone $\mathrm{H} 4$ inhibited activation of the GAL1 and PHO5 promoters in $S$. cerevisiae, suggesting that factors might interact directly with these amino termini (Durrin et al. 1991). Biochemical analyses demonstrated that in mammalian, Drosophila, and yeast systems nucleosome formation could repress transcription, and that the addition of transcriptional activators could significantly alleviate such repression (Workman et al. 1988, 1991; Lorch et al. 1992; Kamakaka et al. 1993). In S. cerevisiae, function of activators on nucleosomal templates was found to require additional factors that might play a coactivating role, perhaps by altering chromatin structure (Lorch et al. 1992). These studies, and the genetic studies discussed below, prompted numerous laboratories to initiate a search for factors that might alter nucleosome structure to facilitate steps required for transcriptional activation.

\section{The SWI/SNF genes}

A group of genes in S. cerevisiae termed SWI/SNF have emerged as strong candidates to encode proteins that directly alter chromatin structure during transcriptional activation (for review, see Winston and Carlson 1992). The SWI genes were identified as being required for appropriate regulation of mating type switching (Stern et al. 1984; Breeden and Nasmyth 1987). A subset of these genes, SWI1, SWI2, and SWI3, were subsequently shown to be necessary for normal transcription of certain yeast genes, including $H O$ an endonuclease required for mating-type interconversion), INO1 (an enzyme required for inositol metabolism), and SUC2 (invertase; required for growth on sucrose and raffinose) and for function of some ectopically introduced activators such as the glucocorticoid receptor (Peterson and Herskowitz 1992; Yoshinaga et al. 1992). The SNF genes were identified as being necessary for SUC2 transcription (Neigeborn and Carlson 1984), and the SNF2, SNF5, and SNF6 genes were shown to be required for appropriate transcription from the long terminal repeat (LTR) of the Ty retrotransposon and for activation by fusion proteins containing the LexA DNA-binding domain and either the GAL4 or Bicoid activation domains (Happelet al. 1991; Laurent and Carlson 1992). In addition, SNF2 (which is identical to SWI21, SNF5, and SNF6 were all shown to function as activators when targeted to a promoter as LexA fusions (Laurent et al. 1991, 1993). These studies implied that SWI and SNF products play an important general role in transcriptional activation.

Genetic studies suggested that the SWI/SNF products might form a complex that actively disrupts chromatin structure. The SIN genes were identified as suppressors of the $s w i^{-}$phenotype, and $\sin 1$ and $\sin 2$ mutants are able to partially suppress mutants of the SWI1, SWI2, and SWI3 genes (Sternberg et al. 1987; Kruger and Herskowitz 1991; Kruger et al. 1995). The sin2-1 mutation was found to lie in the HHT1 gene, which encodes histone H3. Subsequent work showed that a set of six different point mutations, three in histone $\mathrm{H} 3$ and three in histone $\mathrm{H} 4$, all displayed a SIN phenotype in that they would partially suppress the requirement for SWI genes in activation (Kruger et al. 1995). These mutations are all at residues believed to either contact DNA or to be involved in histone-histone contacts within the histone octamer, and thus all mutations might affect nucleosome stability. The SIN1 gene was found to encode a 
protein with homology to HMG-1, a chromatin structural component, and mutations in SINl affect chromosome segregation, supporting a role for this gene in chromatin formation (Kruger and Herskowitz 1991). Lowering the amount of histones $\mathrm{H} 2 \mathrm{~A}$ and $\mathrm{H} 2 \mathrm{~B}$ in the cell can also partially suppress swi/snf phenotypes (Hirschhorn et al. 1992). Thus, alterations in each of the four core histones and in a presumed chromatin structural protein all result in partial suppression of swi/snf mutations, suggesting that destabilization of chromatin structure can partially alleviate the requirement for SWI/SNF function. Although this is consistent with a role for the $S W I / S N F$ genes in altering chromatin structure to allow function of the transcription machinery, it is possible that these genetic interactions do not reflect a direct functional interaction between SWI/SNF proteins and chromatin. It might be that mutation of chromatin components decreases the inhibitory effects of chromatin, thus making activation of transcription more permissive and alleviating a requirement for SWI/SNF in activation that is not related to altering chromatin structure.

Analyses of chromatin structure at the SUC2 promoter in wild-type and snf mutant yeast strains support a direct role for SWI/SNF in disrupting chromatin structure (Hirschhorn et al. 1992; Matallana et al. 1992). When transcription of the SUC2 promoter is induced the micrococcal nuclease sensitivity of the upstream promoter region is increased. Neither this alteration nor full transcriptional induction occurs in snf5 or swi2/snf2 mutants (Hirschhorn et al. 1992). Decreasing histone $\mathrm{H} 2 \mathrm{~A}$ and $\mathrm{H} 2 \mathrm{~B}$ levels not only partially suppresses the swi/snf phenotype of these mutants but also partially restores the disrupted (active) chromatin structure at SUC2. These data offer a strong correlation between the presence of SWI/SNF activity and a disruption of chromatin structure that accompanies transcriptional activation.

The genetic and structural data discussed above are equally compatible with two models for SWI/SNF function: SWI/SNF actively disrupts chromatin structure at promoters to allow increased access of the transcription machinery; or SWI/SNF proteins mediate the interaction between activators and general transcription factors to increase the ability of the general machinery to bind to chromatin. This latter model would postulate that the affinity of the transcription apparatus for sites in chromatin would be increased via SWI/SNF function without any direct effect on nucleosome stability; however, the increased affinity of the transcription apparatus for the promoter would allow it to displace nucleosomes. (Mutations that disrupt nucleosome structure would suppress the need for SWI/SNF function because of the decreased inhibitory effect of the altered nucleosomes.) This model has some support from the observation that the SWI/SNF proteins are associated with RNA polymerase holoenzyme (see below), which is the entity that is currently believed to be recruited to yeast promoters upon activation. Thus, activator contact with SWI/SNF proteins might be expected to increase affinity of holoenzyme for the promoter. This model is argued against, however, by the observation that SWI/SNF-dependent reorganization of chromatin structure at the SUC2 promoter occurs on a crippled promoter that is decreased 20-fold in expression because of a TATA box mutation (Hirschhorn et al. 1992); this mutation should significantly inhibit binding of the transcription machinery, yet chromatin structure is still altered.

Further support for an active role for the SWI/SNF complex in disrupting chromatin structure comes from biochemical studies that demonstrate that the yeast SWI/SNF proteins form a multisubunit complex that alters nucleosome structure and that an apparent human homolog of the yeast SWI/SNF complex has similar properties. The initial evidence that SWI/SNF proteins form a large complex came from genetic studies; maximal activation by LexA fusions to SNF2 and SNF5 require the presence of other SNF and SWI products in the cell (Laurent et al. 1991). A complex of SWI/SNF proteins was subsequently identified by gradient sedimentation followed by immunostaining, and it was shown that the integrity of this complex was disrupted in strains that had null alleles for several swi and snf genes (Peterson et al. 1994). Subsequent purification of the complex indicated that it contains 11 subunits and includes the products of the originally identified genes (SWI1, SWI2/SNF2, SWI3, SNF5, and SNF6) in addition to a newer gene product identified genetically (SNF11) (Cairns et al. 1994; Côté et al. 1994; Treich et al. 1995).

Purified yeast SWI/SNF has activities that are expected for a complex that is actively involved in disrupting chromatin structure during transcriptional activation. It was shown previously that SWI2/SNF2 has ATPase activity (Laurent et al. 1993), so function of the SWI/SNF complex was anticipated to be ATP-dependent: In fact, the purified complex was able to alter nucleosomal structure in an ATP-dependent manner, as measured by disruption of the DNase ladder that is characteristic of stable nucleosomes (Côté et al. 1994). It was also able to facilitate binding of derivatives of the transcriptional activator GAL4, again in an ATP-dependent manner. The SWI/SNF complex binds specifically to cruciform DNA structures, which might resemble the structure of nucleosomal DNA at the position where the DNA enters and leaves the nucleosome and induces positive supercoils in naked plasmid DNA (Quinn et al. 1996). Both of these activities on naked DNA might play a role in nucleosome destabilization, although both activities are not depedent on ATP, so it is unclear how they relate to the ATP-dependent processes of nucleosome disruption and factor loading.

The conservation of the ATP-dependent functions of SWI/SNF was demonstrated by the concomitant analysis of a presumed human homolog of the SWI/SNF complex. Two human genes with a high degree of similarity to yeast SWI2/SNF2 were isolated and were termed Brg1 and $h B r m$ for their similarity to the Drosophila homolog of SWI2/SNF2, Brahma (Kennison and Tamkun 1988; Tamkun et al. 1992; Khavari et al. 1993; Muchardt and Yaniv 1993|. Both hBRM and BRGl proteins were shown to increase the ability of activators to function when 
expressed by cotransfection in mammalian cells, indicating a functional similarity to SWI2/SNF2 (Khavari et al. 1993; Muchardt and Yaniv 1993; Chiba et al. 1994; Singh et al. 1995). An antiserum that recognized both BRGl and hBRM was used to isolate two chromatographically distinct, highly enriched fractions termed hSWI/SNF A and hSWI/SNF B (Kwon et al. 1994). Both of these fractions were shown to disrupt nucleosome structure, as measured by alteration of DNase digestion patterns, and to facilitate the binding of GAL4 derivatives in an ATPdependent manner (Imbalzano et al. 1994; Kwon et al. 1994). In addition, the hSWI/SNF fractions were shown to increase binding of TFIIA and TBP to the TATA sequence on nucleosomal DNA, a step that is potentially rate-determining during transcriptional activation. Subsequent studies with yeast RNA polymerase holoenzyme fractions that contain SWI/SNF also demonstrated an ATP-enhanced loading of TFIIA and TBP to the TATA box, showing that this property is conserved between humans and yeast as well (Wilson et al. 1996). In addition to these functional similarities between yeast and human SWI/SNF complexes, it appears that there will be similarities in the proteins that constitute each complex; a human gene termed INII has been isolated that has extensive similarity to yeast SNF5, and the INI1 protein associates with BRGl and cofractionates with hSWI/SNF (Kalpana et al. 1994).

These data suggested that an evolutionarily conserved function of the SWI/SNF complex is to disrupt nucleosome structure in an ATP-dependent manner to increase binding of transcription factors. Although these results, in combination with the genetic data on SWI/SNF, can be used to make a strong argument that nucleosome disruption is directly involved in activation, pieces of the puzzle are missing that would make the argument convincing: There are no data to show that SWI/SNF activity can be targeted to a promoter by activators, and there are no data that show a requirement for SWI/SNF activity in activation of transcription on nucleosomal templates in vitro, as this remains a technically challenging experiment.

Recent data have shed light on one of these issuestargeting. The ongoing characterization of factors that copurify with the yeast RNA polymerase II holoenzyme complex has shown that the SWI/SNF proteins cofractionate with this complex and can be coimmunopreciptated with the SRB proteins, the hallmark members of holoenzyme (Wilson et al. 1996). The SWI/SNF complex can be isolated from yeast without associated holoenzyme (Cairns et al. 1994; Côté et al. 1994), implying that the interaction with holoenzyme can be disrupted under certain chromatographic procedures and/or that some SWI/SNF is present in the cell in a form that is not associated with holoenzyme. Holoenzyme is a complex that contains numerous general transcription factors in addition to RNA polymerase II and the SRB proteins (for review, see Emili and Ingles 1995|. Activators function efficiently in vitro in reactions that contain holoenzyme, and direct recruitment of holoenzyme to a promoter by activators has been proposed as a mechanism of activa- tion (Kim et al. 1994; Koleske and Young 1994; Barberis et al. 1995). Holoenzyme contains a subset of proteins that interact with the carboxy-terminal domain (CTD) of RNA polymerase II-termed mediator (Kim et al. 1994), and the yeast SWI/SNF proteins also copurify with mediator (Wilson et al. 1996). Both the holoenzyme and mediator fractions have the expected ATP-dependent nucleosome disruption activity of SWI/SNF, and holoenzyme can assist TBP/TFIIA loading to a nucleosomal template in an ATP-enhanced manner. These data suggest that the yeast SWI/SNF proteins are associated with the complex that forms with the RNA polymerase CTD and that SWI/SNF activity might be targeted via association with holoenzyme. These biochemical observations were foreshadowed by the genetic observation that $\sin$ mutations, which suppress SWI/SNF function, also suppress the auxotroph phenotypes caused by CTD truncation (Peterson et al. 1991). It is unclear whether human SWI/SNF proteins are also associated with RNA polymerase holoenzyme, so the generality of these findings has not been established yet.

The data pertaining to SWI/SNF are compatible with a simple, testable model for transcriptional activation in yeast (Fig. 2). The model expands on previous proposals that recruitment of holoenzyme to a promoter is a critical aspect of activation (Barberis et al. 1995). If holoenzyme is recruited in a robust manner, nucleosomes are displaced as a result of the high affinity of holoenzyme binding, and SWI/SNF activity is not needed (Fig. 2). If holoenzyme recruitment is less robust, or there is a refractory chromatin configuration at the promoter, then the SWI/SNF activity associated with the holoenzyme disrupts nucleosomal structure to facilitate binding. This model explains why some promoters in which nucleosome disruption occurs with activation (e.g., PHO5) do not require SWI/SNF action, whereas other promoters such as SUC2 do require SWI/SNF action. Such a model yields several testable hypotheses: SWI/SNF function should be targeted by some activators in vitro when holoenzyme fractions are used; weak activators should require SWI/SNF function in vivo in certain chromatin settings, whereas strong activators in the same setting should not; and mutations in SWI/SNF genes should exist that disrupt holoenzyme/SWI/SNF interaction, that only affect regulation of certain promoters, and that do not affect the general nucleosome disrupting abilities of SWI/SNF. A key point to consider with this model concerns the amount of SWI/SNF in yeast and whether all holoenzyme is associated with SWI/SNF. Estimates of amounts of SWI/SNF range from 100 to 200 complexes per cell as determined by fractionation (Cairns et al. 1994; Côté et al. 1994), which would provide enough to associate with $\sim 10 \%$ of holoenzyme, to nearly stoichiometric with holoenzyme (1000-2000 copies per cell), as determined by comparative Western analysis (Wilson et al. 1996). If some holoenzyme is associated with SWI/ SNF and some is not, it is critical to have a mechanism to target the SWI/SNF-containing holoenzyme to the proper promoter.

The model presented here (Fig. 2) simplifies the issue 

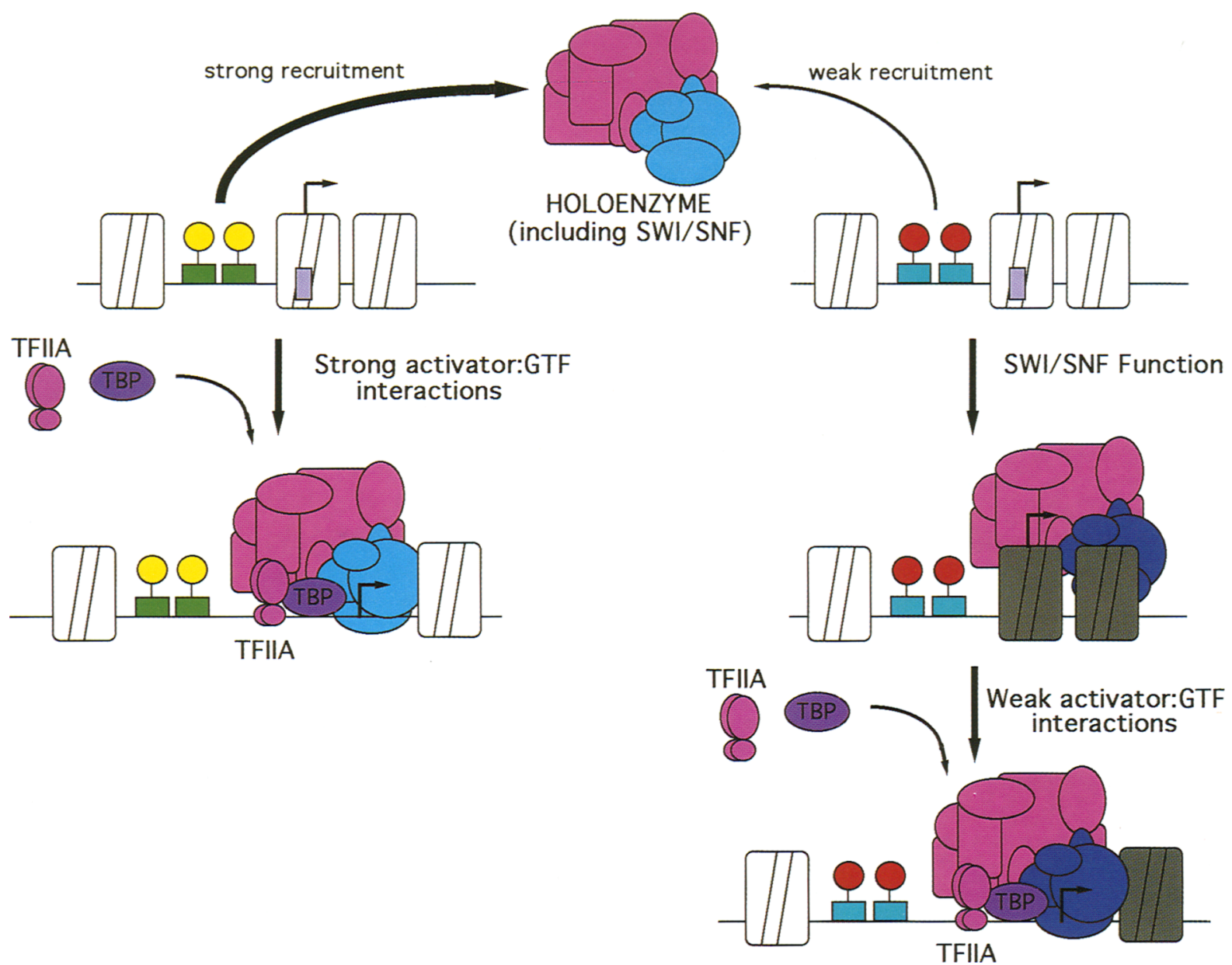

Figure 2. A model for function of SWI/SNF during activation in yeast. It is proposed that SWI/SNF is targeted to promoters via association with holoenzyme but that SWI/SNF function is only required when activator-holoenzyme contacts are insufficiently robust to allow holoenzyme to displace nucleosomes.

of how the activator initially finds its binding site by placing the activator on DNA prior to interaction with SWI/SNF or the general machinery. In some promoters (e.g., PHO5) the activator binds to linker DNA, whereas in other promoters activators must bind to a nucleosomal site. It is possible, if not likely, that SWI/SNF will mediate activator binding in vivo to nuclcosomal sites, as it does in vitro, and that on certain promoters there might be a concerted reaction that loads activators and holoenzyme in a SWI/SNF-dependent manner. It is also possible that on certain promoters SWI/SNF acts independently of holoenzyme, whereas on others its action is targeted via association with holoenzyme.

\section{ATP-dependent chromatin reorganizing activities in Drosophila}

The biochemical studies of SWI/SNF were motivated by a desire to understand the mechanistic basis for swi/snf mutant phenotypes; a different approach that has uncovered ATP-dependent chromatin reorganizing activities has come from the development of in vitro chromatin reconstitution systems that seek to recapitulate changes in chromatin structure on regulated Drosophila genes. The Drosophila heat shock protein genes, particularly HSP 70 , have served as an important model system for characterizing changes in chromatin structure at promoters since 1980 (Wu 1980). The inactive HSP70 gene is bound by a sequence-specific activator termed GAGA factor, the general transcription factor TFIID, and a transcriptionally engaged RNA polymerase that is paused at +25 (for review, see Lis and Wu 1993). DNase hypersensitive sites have been characterized in the promoter region, and their formation requires both the TATA sequence and the GAGA binding sites. In an effort to understand the genesis of these hypersensitive sites, an S190 extract from Drosophila embryos was developed that could create appropriately spaced nucleosomes on plasmid templates in vitro and that could be used to study the effects of transcription factor binding on chromatin structure (Becker and Wu 1992).

Binding of GAGA factor to HSP70 templates that have been assembled into chromatin with these extracts generates a disruption in the micrococcal nuclease digestion pattern at the promoter and also results in DNase hypersensitivity that is similar, but not identical, to the hy- 
persensitivity that occurs in vivo (Tsukiyama et al. 1994). These changes in nuclease accessibility require hydrolyzable ATP. Subsequent studies have shown that a separate activator, heat shock factor, can also create alterations in nuclease sensitivity on chromatin assembled by these extracts, and that restriction enzyme access to sites on these templates is increased in an ATP. dependent manner (Tsukiyama and Wu 1995; VargaWeisz et al. 1995; Wall et al. 1995). The increased access of restriction enzymes and the increased perturbation of structure by factor binding has been proposed to result from an increased mobility of nucleosomes; nucleosome spacing on assembled templates in these extracts can be altered by changing salt concentration under appropriate conditions, and this salt-induced change also occurs in an ATP-dependent manner (Varga-Weisz et al. 1995). In parallel studies, a Drosophila extract prepared under somewhat different conditions could assemble ordered nucleosomal arrays, and the fidelity of these arrays was altered by binding of the activator GAL4, also in an ATPdependent manner (Pazin et al. 1994).

These data indicate that Drosophila embryos contain proteins that can alter nucleosome mobility, increase restriction enzyme access, and permit activator-dependent alterations in chromatin structure, all in an ATP-dependent manner. It is not clear whether these capabilities are all the result of one complex of proteins or whether several different complexes are involved.

\section{NURF}

In an elegant study, Tsukiyama, $\mathrm{Wu}$, and colleagues have purified an activity from Drosophila embryo extracts, termed NURF (nucleosome remodeling factor), that is able to facilitate perturbation of chromatin structure by the GAGA factor and increase restriction enzyme access in an ATP-dependent manner (Tsukiyama and Wu 1995). The final fraction from this purification contains four predominant polypeptides and was capable of promoting GAGA factor and ATP-dependent disruption of micrococcal patterns at low ratios of NURF to nucleosomes (very approximately, 10 nucleosomes per NURF complex). NURF also displayed activities similar to SWI/ SNF; it could alter the 10-bp DNase digestion ladder on a mononucleosome in an ATP-dependent manner and facilitate binding of GAGA factor to a mononucleosome in an ATP-dependent manner. These data led to a model in which NURF alters nucleosomal DNA structure in an ATP-dependent manner, which then facilitates GAGA factor binding (Tsukiyama and $\mathrm{Wu} \mathrm{1995).} \mathrm{These} \mathrm{alter-}$ ations might conceivably result in an increased mobility of nucleosomes on large templates (Varga-Weisz et al. 19951, with concomitant changes in micrococcal sensitivity and restriction enzyme access, although further study is needed to understand how the increased restriction enzyme access and nuclease access are related to each other and to nucleosome mobility.

In a striking convergence of the biochemical studies of Drosophila extracts and the genetic studies of SWI/SNFrelated factors, one of the subunits of NURF has been identified as the product of the ISWI (imitation switch) gene (Tsukiyama et al. 1995). The ISWI gene was identified in a low-stringency Southern screen for Drosophila factors with sequence similarity to yeast SWI2/SNF2 (Elfring et al. 1994). The Drosophila gene with highest homology to SWI2/SNF2 is Brahma (Brm); however, ISWI has significant identity to SWI2/SNF2 (and BRM and the human genes $h B R M$ and $B R G 1$ ) over a 460-amino-acid ATPase domain. A human gene, hSNF2L /Okabe et al. 1992 ), is $75 \%$ identical to ISWI over its entire length and therefore appears to be the human homolog of ISWI. A putative yeast homolog (termed YB95) has also been identified, indicating that ISWI is extensively conserved (Tsukiyama et al. 1995).

\section{NURF and SWI/SNF as facilitators of activation}

It is attractive to postulate that the NURF and SWI/SNFrelated complexes represent two distinct classes of ATPdependent nucleosome reorganizing activities that both function during activation of gene expression, with the separate complexes being used in separate circumstances. Each complex has been shown to alter nucleosome structure in a manner that facilitates transcription factor interaction in vitro. The extensive conservation of the ATPase of each complex (SWI2/SNF2 and ISWI) from yeast through humans suggests an important role for each complex in vivo. The nucleosome remodeling activities of each complex might be used during the various stages of transcription that are inhibited by nucleosomes (see Fig. 1) but also might be used in chromatin assembly or in recombination reactions. The requirement of yeast SWI/SNF genes for function of several activators (Laurent and Carlson 1992; Peterson and Herskowitz 1992; Yoshinaga et al. 1992), the requirement of brm for appropriate maintenance of homeotic gene expression in Drosophila (Kennison and Tamkun 1988; Tamkun et al. 1992), and the association of yeast SWI/ SNF with RNA polymerase holoenzyme all offer support for a role of the SWI/SNF complex in transcriptional activation (Wilson et al. 1996). There are no data on the phenotype of ISWI mutations in Drosophila; it will be intriguing to test the hypothesis that NURF is required on genes that utilize GAGA factor in vivo.

Although the biochemical activities of each complex argue for a direct role in the transcription activation process, it is important to emphasize that neither activity has been shown explicitly to play a role in transcriptional activation in vitro. The availability of model transcription systems (e.g., GAL4-driven promoters) and highly fractionated complexes should allow an assessment of the role of these complexes in activation; however, a more attractive in vitro experiment would be to use a natural promoter that requires either SWI/SNF or NURF activity in vivo to characterize the role that these complexes might play. Unfortunately, there is a major stumbling block to such a strategy: There are no mammalian or Drosophila genes whose regulation has been demonstrated to require SWI/SNF or NURF complexes in vivo, and there are no established in vitro chromatin 
systems to study the yeast genes, such as SUC2 or HO, that require SWI/SNF function. Thus, although an important role for these complexes in activation is likely, there is a need for significant further experimentation for a rigorous argument to be made.

It is conceivable that the SWI/SNF and NURF complexes play redundant roles in vivo. Both display similar abilities to disrupt nucleosomal structure and facilitate factor loading (Côté et al. 1994; Imbalzano et al. 1994; Kwon et al. 1994; Tsukiyama and Wu 1995). There are apparent differences in the ATPase activities of the two complexes, however, as the ATPase activity of NURF is modestly stimulated by nucleosomal DNA and is not significantly stimulated by naked DNA (Tsukiyama and Wu 1995), whereas the SWI/SNF ATPase activity can be stimulated by naked DNA (Laurent et al. 1993; Côté et al. 1994; Kwon et al. 1994). In addition, the ISWI ATPase domain will not substitute for the SWI2/SNF2 ATPase domain in yeast gene replacement studies, whereas the BRM ATPase domain will (Elfring et al. 1994). These data, in conjunction with the greater size and complexity of SWI/SNF-related complexes $(2000 \mathrm{kD} ; 11$ or more peptides) versus the NURF complex (500 kD, 4 peptides), suggest that the two complexes play distinct roles.

Sorting out the relative roles and functions of these complexes will be complicated further by the number of SWI/SNF-related complexes in mammals. There are at least two chromatographically distinct complexes in HeLa cells, and the two mammalian homologs of SWI2/ $S N F 2, h B R M$ and $B R G 1$, each have two splice variants (Khavari et al. 1993; Muchardt and Yaniv 1993; Chiba et al. 1994). The different splice variants of Brgl have been shown to have differential effects on cell growth. Both $B R G 1$ and $h B R M$ can inhibit cell growth, and both interact with the hypophosphorylated form of the retinoblastoma protein $(\mathrm{Rb})$; the two differentially spliced forms of Brgl show different abilities to interact with $\mathrm{Rb}$ and to slow cell growth (Dunaief et al. 1994; Strober et al. 1996). These data raise the possibility of multiple forms of mammalian SWI/SNF-related complexes, each containing different members of the mammalian homologs of the SWI2/SNF2 genes, and each potentially having different abilities to function in chromatin.

\section{Chromatin-specific activators}

If the recruitment of chromatin remodeling complexes is an important aspect of activation, and it is not obligatory that these activities be recruited with general transcription factors such as holoenzyme, then one might expect that certain activators would function solely by recruiting remodeling complexes. This hypothetical class of activators would be expected to function only on chromatin templates. GAGA factor in Drosophila and LEF-1 in mammals might be members of such a class, as they seem to function in a chromatin-specific manner.

GAGA factor binding sites are required for establishment of proper chromatin structure on the promoters of the HSP26 and HSP7O genes (for review, see Lis and Wu 1993). Purified GAGA factor has been shown to remodel chromatin structure in conjunction with NURF (Tsukiyama et al. 1994; Tsukiyama and Wu 1995) and has been shown to alleviate repression of transcription in vitro on templates that have been repressed by histone H1 (Crosten et al. 1991). The factor does not stimulate transcription in vitro on naked DNA templates. In mammalian systems, LEF- 1 has been shown to bend DNA and has been proposed to play an important architectural role in establishing proper enhancer structure /Geise et al. 1992) but does not stimulate transcription on naked DNA templates. LEF-1 is able, however, to stimulate transcription significantly from the HIV enhancer in vitro when that enhancer has been assembled into a spaced nucleosomal array (Sheridan et al. 1995). It will be important to determine whether specific domains of factors such as these are required for function on chromatin and whether these domains are demonstrably different from characterized transcriptional activation domains. If remodeling of chromatin is a critical aspect of activation, then it would be anticipated that there would be chromatin-specific activation domains that might direct remodeling.

\section{Chromatin structure and repression of gene expression}

The complexity of genes believed to be involved in activation on chromatin templates is daunting, and there appears to be at least a similar degree of complexity in genes that might play a role in establishing and maintaining repressive chromatin structures. The importance of maintaining stable repression of gene expression is most apparent in multicellular organisms, where it is essential that developmental regulatory genes be active only in specific cell types. In fact, there are extensive genetic studies dating from the discovery of the Polycomb gene in Drosophila in 1947 implying that there is a large network of genes that are required to maintain repression of transcription during development (referred to as the Polycomb-group, or Pc-G, in Drosophilal. These genes were among the earliest identified in screens for homeotic transformations that led to abnormal expression of sex combs on the fly. The general importance of these gene products is indicated by the isolation of human homologs of Pc-G genes as proto-oncogenes fe.g., $B m i-1$, which collaborates with Myc in inducing tumors; Haupt et al. 1991; van Lohuizen et al. 1991b). It is currently believed that these gene products function by establishing a stable, repressed chromatin structure over promoters (see below).

PC-G genes, in contrast to SWI2/SNF2 and ISWI, do not appear to be conserved in yeast. A role for chromatin structure in gene repression is well characterized in yeast, however, and the mechanisms might be general. The complexity of the genes potentially involved in repression in chromatin precludes a thorough review of this area here; recent reviews have covered silencing, SSN6/TUP1, and the PC-G in greater detail /Orlando and Paro 1995; Roth 1995; Simon 1995). Topics such as position-effect variegation are also relevant but beyond the scope of this review. The remainder of this review will 
focus on data indicating that repressive complexes are targeted to specific genes, potentially "coating" chromatin via contact with the amino termini of nucleosomes, and it will discuss the possibility that these repressive complexes function in direct competition with the remodeling complexes believed to be involved in activation.

\section{Silencing at telomeres and at $H M L$ and $H M R$}

A very potent repression of transcription in $S$. cerevisiae, silencing, occurs near telomeres and at normally unexpressed copies of yeast mating-type genes $H M L$ and $H M R$. This type of repression is perhaps related to the condensation of chromatin that occurs in heterochromatin in multicellular organisms, as the $H M$ loci and telomeres share with heterochromatin the properties of late replication, "spreading" of silencing, and variegation (for references, see Hecht et al. 1995). It appears that transcriptional repression at telomeres and at the silent mating type loci $H M L$ and $H M R$ in yeast is mediated by a complex that contains (at minimum) the nucleosome and several SIR (silent information regulator) gene products. This repression also involves other proteins, such as the sequence-specific binding protein RAPl, which binds promoters that are not silenced and also to silenced regions, and the origin recognition complex |ORC), which binds specifically to DNA replication origins (Rine and Herskowitz 1987; Shore and Nasmyth 1987; Aparicio et al. 1991; Laurenson and Rine 1992; Chien et al. 1993; Renauld et al. 1993; Morettti et al. 1994; Hecht et al. 1995; for review, see Newlon 1993; Shore 1994). A direct involvement of histones in silencing was suggested by studies showing that deletion of the amino termini of either histone $\mathrm{H} 3$ or histone $\mathrm{H} 4$ derepressed the $H M$ loci and genes located near telomeres (Kayne et al. 1988; for review, see Hecht et al. 1995). Genetic studies have also implicated several other genes in this repression, and current data suggest that SIR3 and SIR4 might interact directly with histone amino termini to nucleate a repressive structure.

The SIR genes were isolated via their requirement for efficient repression at the $H M$ loci (for review, see Rine and Herskowitz 1987), and the SIR2, SIR3, and SIR4 genes were subsequently found to be necessary for repression at telomeres (Aparicio et al. 1991). Telomeres create a heritably repressed state that can extend for varying distances along the chromosome from the telomere to adjacent genes, and that varies in extent of spreading in genetically identical cells (producing a variegated phenotype) (Gottschling et al. 1990). Gene replacement strategies have been used to show that if a distal gene is repressed by a telomere in a given cell, a proximal gene in the same cell is also repressed, indicating that repression spreads from the telomere outward (Renauld et al. 1993). SIR3 has been directly implicated in this spreading by studies showing that overexpression of SIR3 leads to increased spreading (Renauld et al. 1993). As in silencing of the $H M$ loci, potential targets of the SIR3 gene include the amino termini of histones $\mathrm{H} 3$ and
$\mathrm{H} 4$ : Deletions and point mutations in these amino termini cause derepression of $H M$ loci and telomeres, and the regions delineated by these mutations differ from the regions of the amino termini that are required for transcriptional activation (for an overview, see Hecht et al. 1995; Roth 19951.

Recent experiments offer support for a direct interaction between SIR 3 and SIR 4 and the amino termini of H3 and $\mathrm{H} 4$ (Hecht et al. 1995). Glutathione $S$-transferase (GST) pull-down experiments were used to show that SIR3 and SIR4 could interact with the amino termini of histones $\mathrm{H} 3$ and $\mathrm{H} 4$ but not the amino termini of histones $\mathrm{H} 2 \mathrm{~A}$ and $\mathrm{H} 2 \mathrm{~B}$, which are similarly charged. There was a very good, but not absolute, correlation between the effects of histone mutations on interaction in this assay with the effects on derepression in vivo. Finally, SIR3 localizes to specific perinuclear regions, similar to those where the telomere-specific binding protein RAP1 localizes (Palladino et al. 1993), and histone H3 and H4 deletions were shown to cause delocalization of SIR3 in vivo (Hecht et al. 1995).

Although these studies offer strong support for the hypothesis that SIR3 plays an essential role in directing a repressive structure that interacts with histone amino termini (see Fig. 3), there are not yet direct functional studies to corroborate this hypothesis. Silencing is known to affect the general accessibility of chromatin in vivo, as shown by decreased restriction enzyme and DAM methylase access to DNA in silenced regions (Gottschling 1992; Loo and Rine 1994). By analogy with the increase in restriction enzyme accessibility afforded by NURF and related complexes in vitro, a more complete understanding of the role that SIR3 plays in establishing a repressed structure would be aided by the establishment of in vitro systems where SIR3-containing complexes were shown to decrease access of proteins to DNA, either over the already refractory ground state of nucleosomal templates assembled in vitro or against action of complexes such as SWI/SNF.

A repressive complex that contains SIR3 is expected to contain numerous components. Two-hybrid studies have been used to show that SIR3 and SIR4 will interact with each other and with the sequence-specific factor RAPl (Moretti et al. 1994). Genetic evidence indicates a critical role for the multisubunit ORC in establishing silencing at $H M$ loci (for review, see Newlon 1993), and it has been suggested that ORC might also play a role at telomeres (Palladino and Gasser 1994). Other proteins, such as ABF1 and RIF1 are involved at silencing at $H M$ loci, and there might be further factors needed at telomeres that remain uncharacterized. It is not clear which of these proteins are associated in a stable complex (SIR2, SIR3, SIR4, and nucleosomes?), which are involved in targeting the complex (SIR1, RAP1?), and whether the involvement of ORC is caused by a necessary role for replication in establishing the silenced state, and/or whether ORC plays a more direct role in establishing a refractory chromatin structure (see Chien et al. 1993; Fox et al. 1995).

Repression in silenced regions can be modulated by 
activators. Overexpression of the PPRl activator caused derepression of the URA3 gene when the gene was located next to a telomere, and repression of a telomeric GAL4-driven reporter was derepressed by GAL4 expression in an activation domain-dependent manner (Aparicio and Gottschling 1994). This derepression could not occur in cells that were arrested in $G_{0}, G_{1}$, or early $S$ but could occur in cells that were blocked in $\mathrm{G}_{2} / \mathrm{M}$. This observation suggests that the repressive structure might have to reform in $G_{2} / M$, allowing a window where formation of the repressive complex was in competition with activator function, and that activator function can block formation of a gene into a silenced state. Such a model is consistent with studies in multicellular organisms that imply that activator and Pc-G binding are mutually exclusive (see below). If activators do target remodeling complexes, then remodeling complexes and silencing complexes might be placed in direct competition on chromatin, with activator function playing a critical role in determining the resultant chromatin configuration.

\section{SSN6/TUP1}

In contrast to silencing, which creates a heritable repressed state that is rarely derepressed in a natural setting, the SSN6 and TUPl proteins play a role in repressing genes that are derepressed under appropriate growth conditions, such as the a-specific genes /repressed in $\alpha$ cells), the SUC2 gene and the GAL1/GAL10 genes (for review, see Johnson 1995; Roth 1995/. Repression by these proteins has been strongly correlated with the establishment of an ordered nucleosomal array over affected promoters. Neither SSN6 nor TUP1 is a sequencespecific DNA-binding protein. Rather, they are targeted to specific promoters via an interaction with sequencespecific factors such as $\alpha 2 /$ MCM1 (Johnson 1995). Targeting of either SSN6 or TUP1 to a promoter via fusion with the LexA DNA-binding domain also causes repression (Tzamarias and Struhl 1994). The LexA-SSN6 protein requires TUP1 expression to repress, whereas, intriguingly, LexA-TUP1 does not have an absolute requirement for SSN6, suggesting that TUPl may be the more directly acting of the two proteins. These proteins fractionate from yeast cells in a large complex $(1200 \mathrm{kD}$; Williams et al. 1991), raising the possibility that they might nucleate a repressive complex on chromatin.

The chromatin structure of numerous genes that are regulated by SSN6/TUP1 has been examined, and in all cases there is an ordered chromatin structure under repressive conditions (Roth 1995). Derepression of several a-specific genes, the SUC2 gene and the GAL1/GAL10 genes is accompanied by an alteration in chromatin structure (Roth et al. 1990; Shimizu et al. 1991; Axelrod et al. 1993; Cavalli and Thoma 1993; Cooper et al. 1994; Hirschhorn et al. 1995). The establishment of an ordered nucleosomal array on the a-specific genes requires SSN6 and TUP1 (Cooper et al. 1994), whereas SSN6 is necessary to establish the repressed structure on the SUC2 gene (Matallana et al. 1992). Establishment of a repressed state requires histone amino termini, raising the possibility that repressive structures form that directly involve nucleosomes (Roth et al. 1992). The same conceptual difficulty discussed above for activation of transcription in chromatin pertains here; it is unclear whether there is a correlation between an ordered array and repressed genes because SSN6 directs a nucleosomal structure that represses steps required for transcription (Fig. 1), or because SSN6/TUP1 inhibits function of the general transcription machinery, and the resultant lack of transcription allows nucleosomes to form an ordered structure. One prediction of the latter model-in which a repressed structure does not require SSN6 or TUP1 for formation-would be that a promoter crippled by mutation of TATA sequences and/or upstream activating sequences would be packaged in ordered nucleosomes even in the absence of SSN6/TUP1 function. This is not true; mutation of either SSN6 or TUP1 alters nucleosome structure even on a crippled promoter, supporting a direct role for these proteins in creating a repressive chromatin state (Cooper et al. 1994).

Function of activators certainly involves direct interaction of the activators with the general transcription machinery in addition to effects on chromatin structure; it seems likely that global repressors such as SSN6/ TUPl also function via both mechanisms. SSN6/TUPl are able to repress transcription in vitro in the absence of chromatin assembly (Herschbach et al. 1994). The extent of repression (4-fold) is much lower than seen in vivo (>100-fold), which might reflect either the difficulties of recapitulating full effects in an in vitro system or might indicate the extent to which SSN6/TUP1 functions via chromatin structure. In regulated settings, it would seem most efficient to use multiple mechanisms to achieve repression, as is likely to be the case for regulated activation.

\section{Pc-G}

The emerging roles for chromatin structure in repression of yeast genes serve as a paradigm for understanding how the $P C-G$ genes might function to maintain repressed states in multicellular organisms. The Pc-G genes were found in screens for effects on development in Drosophila, and this conserved set of genes is understood in most detail in this organism. There are 13 genetically identified members of this group, with perhaps at least an equal number remaining undiscovered (for review, see Simon 1995). Biochemical studies and in situ localization studies are interpreted most simply as indicating that the Pc-G gene products form several large complexes. The proteins encoded by $\mathrm{Pc}$, polycomb-like $(\mathrm{Pcl})$ and polyhomeotic ( $\mathrm{Ph})$, all localize to an identical set of $\sim 100$ bands in polytene chromosomes (Zink and Paro 1989; DeCamillis et al. 1992; Franke et al. 1992; Lonie et al. 1994). This remarkable colocalization, with data indicating that $\mathrm{Pc}$ and $\mathrm{Ph}$ coimmunoprecipitate and fractionate in an apparent complex $>2 \mathrm{MD}$ in size, suggests that these proteins are found in a single complex (Franke et al. 1992). The products of the posterior sex combs (Psc) 
gene and the suppressor 2 of zeste $[\mathrm{Su}(\mathrm{z}) 2]$ gene colocalize with $\mathrm{Pc}, \mathrm{Ph}$, and $\mathrm{Pcl}$ at a subset of sites. $\mathrm{Su}|z| 2$ and $\mathrm{Psc}$ can also localize independently of each other and are also found together at sites where $\mathrm{Pc}, \mathrm{Pcl}$, and $\mathrm{Ph}$ are not found (Rastelli et al. 1993). Thus, Psc does not always colocalize with $\mathrm{Pc} / \mathrm{ph} / \mathrm{Pcl}$, and it would seem most likely that Psc can sometimes be found in a different complex [sometimes containing Su|z/2?] in vivo. Fractionation of these complexes will be required to test these speculations concerning the multiplicity of Pc-G complexes.

The repressive effects of the Pc-G have been studied most thoroughly with the adjacent Bithorax complex $(B X-C)$ and Antennapedia complex $(A N T-C)$ gene clusters. These clusters each encode several homeotic genes required for appropriate development, and many of the $P c-G$ genes were initially identified as mutations that altered expression of these genes, resulting in misexpression of sex combs (Lewis 1978; Struhl 1981; Ingham 1983). Regulatory elements of the Antp and Scr genes of the $A N T-C$ and the $U b x, a b d A$, and $a b d B$ genes of $B X-C$ have been shown to confer regulation by the $P c-G$ on a linked $l a c Z$ reporter when introduced into Drosophila by P-element-mediated transformation (Zink et al. 1991; Busturia and Bienz 1993; Simon et al. 1993; Chan et al. 1994; Gindhart and Kaufman 1995). These sequences (termed PREs) are therefore believed to target Pc-G induced repression, although the mechanism by which these sequences are recognized by the Pc-G proteins is not clear, as no Pc-G protein has been shown to bind specifically to DNA. The most well-delineated completely functional PRE is a $5.6-\mathrm{kb}$ fragment of the Ubx regulatory region (Chiang et al. 1995), and a 1.6-kb fragment from this region bestowed partial PRE function (Chan et al. 1994), so it does appear that there are simple, short sequence elements that can target Pc-G repression.

Once targeted, the Pc-G maintains repression of homeotic genes, apparently through the creation of a refractory chromatin structure. In considering Pc-G function, it is important to recall that the Pc-G must maintain repression of loci over numerous cell divisions: expression of homeotic genes is appropriately established in Pc-G mutant embryos, but these mutants lose repression as the fly develops, resulting in misexpression of homeotic genes later in development (for review, see Paro 1995; Simon 1995). Thus, the Pc-G proteins must perform a function similar to the proteins involved in silencing in yeast, and similar "coating" models have been proposed for both forms of repression (Paro 1990). Studies employing UV-cross-linking followed by immunoprecipitation have shown that the Pc protein is physically associated with sequences corresponding to entirety of the $U b x$ and $A b d A$ genes $(\sim 300 \mathrm{~kb})$, whereas it is not associated with the adjacent $A b d B$ gene (Orlando and Paro 1993). Many of these sequences do not contain high-affinity Pc-G-binding sites when separated from the $B X-C$ (Chiang et al. 1995); high affinity binding in this case is measured by the ability to confer repression on a linked lac $Z$ gene and by the ability to target $\mathrm{Pc}$ as visualized by indirect immunofluorescence. Four fragments from this region, each $5-10 \mathrm{~kb}$ in length, do confer highaffinity binding by Pc. These data are consistent with a model similar to that proposed for silencing in yeast: The high affinity binding sites target and nucleate formation of a Pc-G complex, and the complex then spreads to adjacent regions, creating a stably repressed chromatin structure.

Establishment of a repressed chromatin state with similar properties to heterochromatin and/or silenced domains is an attractive hypothesis for Pc-G function, but is there direct evidence for formation of an altered chromatin structure? Suggestive evidence abounds: The Pc protein contains a region termed the "chromodomain" that is conserved with the heterochromatinspecific protein HP1 (Paro and Hogness 1991); the Drosophila homolog of the SWI2/SNF2 gene, BRM, was isolated as a suppressor of $\mathrm{Pc}$ mutations (Kennison and Tamkun 1988; Tamkun et al. 1992); the ability of sequence-specific DNA-binding proteins to interact with $P_{C}$-G-repressed genes is inhibited in a manner similar to inhibition by stable nucleosomes (Zink and Paro 1995; McCall and Bender 1996). Perhaps the most compelling evidence that the Pc-G establishes a repressive chromatin structure is that some PC-G genes can modify position-effect variegation (PEV) and some genes required for PEV can interact genetically with the Pc-G /Grigliatti 1991।. PEV is presumed to result from spreading of heterochromatin, and similar variegated phenotypes occur through silencing mechanisms in yeast, so these results link Pc-G both to heterochromatin formation and to a mechanistic similarity with silencing. These observations all point to a $\mathrm{Pc}-\mathrm{G}$ induced, refractory chromatin structure, but a physical association between Pc-G proteins and nucleosomes has not been detected yet, and there are no functional in vitro systems where Pc-G repression can be recapitulated and characterized.

Several results indicate that the repressed structure established by the Pc-G is not completely impervious to factor interaction and that the repression can be regulated by upstream activator proteins. Insertion of a GAL4-regulated reporter into the $U b x$ regulatory region places GAL4-driven activation under control of the Pc$\mathrm{G}$; however, T7 RNA polymerase transcription of genes in the same region is not repressed by the Pc-G (McCall and Bender 1996). Thus, not all sequence-specific DNAprotein interactions are blocked by Pc-G function. In a related experiment, a reporter containing both a PRE and GAL4 sites was integrated at sites that do not normally bind Pc-G proteins. GAL4 binding and Pc binding under these conditions appeared to be mutually exclusive when visualized by in situ hybridization (Zink and Paro 1995). Moreover, increased expression of GAL4 decreased Pc binding, suggesting a competition between the activator and the Pc-G in this setting. A direct link between activators and Pc-G repression is further supported by experiments where Pc-G members are targeted to promoters via heterologous DNA-binding domains. GAL4-Pc-G fusions repress different promoters to different extents in flies (Müller 1995), and LexA-Pc-G fusions are able to repress expression in mammalian cells 
in a manner that varies according to the activation domain of the affected activator (Bunker and Kingston 1994). Thus, as discussed above for silencing in yeast, it appears that activators might block the function of the Pc-G proteins, either directly or via their potential to recruit remodeling complexes that might block formation of a repressed chromatin state.

\section{Nucleosome mobility as a target for regulatory complexes}

All of the above studies are consistent with a model that invokes nucleosome mobility as a key controlling mechanism in gene regulation (Fig. 3). Nucleosomes are frequently thought of as being static structures in which the histone core maintains stable contact with a particular 145-bp sequence. In fact, isolated nucleosomes have been clearly demonstrated to be mobile, meaning that they can readily change translational position on a piece of DNA, and this mobility can be affected by changes in solution conditions (Meersseman et al. 1992). Increased nucleosome mobility might result from the sliding of nucleosomes along DNA, or from the direct transfer of the nucleosome from one segment of DNA to an adjacent segment in a mechanism similar to that proposed for "stepping around" a transcribing RNA polymerase (Studitsky et al. 1994). An ATP-dependent activity in Drosophila extracts can increase mobility, and decreased mobility represses RNA polymerase III transcription, leading to previous proposals that regulated mobility might play a critical role in activation and repression (Ura et al. 1995; Varga-Weisz et al. 1995). Increased mobility of nucleosomes would increase the probability that a binding site for an activator or for a general transcription factor would become accessible, whereas decreased mobility would decrease that probability. Once a factor is bound, a nucleosome with increased mobility might be displaced more readily, either by sliding to an adjacent sequence or by transferring to a different stretch of DNA or to histone-binding proteins (see below). ATPdependent remodeling activities such as NURF and SWI/ SNF have been shown to increase accessibility of nucleosomal DNA to nucleases and sequence-specific binding factors; an increased mobility of nuclesomes is one po- tential cause for these observations. A stable structure formed between the SIR proteins and histone amino termini in yeast, as proposed for silencing, would very likely inhibit nucleosome mobility by adding the extra constraint of stable histone--regulatory protein interactions to that of histone-DNA interactions.

By this model, repressors could function both by directing formation of a structure that decreased nucleosome mobility and by blocking the recruitment of factors that increased mobility, whereas activators would function in the opposite manner. The likelihood that repressors and activators can both affect both types of remodeling complexes is favored by the a priori assumption that a dual capability for a regulatory protein would provide for more potent action. An ability to affect both types of complexes would explain why activators can help displace Pc-G complexes and can also prevent silencing (Aparicio and Gottschling 1994; Zink and Paro 1995). There is no necessity, and in fact no expectation, that activation and repression mechanisms that use these complexes will function solely through effects on chromatin structure; direct effects on general transcription factor function are also likely.

\section{Structural considerations}

To test the above hypothesis, and to test most any hypothesis concerning transcriptional regulation on chromatin, a deeper understanding of the numerous aspects of chromatin structure is needed. Below we briefly mention several aspects of chromatin structure that are likely to be critical to the function of regulatory complexes. These topics are all worthy of lengthy review; the brief descriptions below are meant to point out the complexity of the issues involved.

\section{Histone amino termini}

The amino termini of histones are not ordered in the available crystal structures of nuclesomes (Richmond et al. 1984; Arents et al. 1991; Arents and Moudrianakis 1993/ and appear to stick out of the nucleosome core. This allows their positively charged surfaces to interact with DNA that is either bound to the core nucleosome,

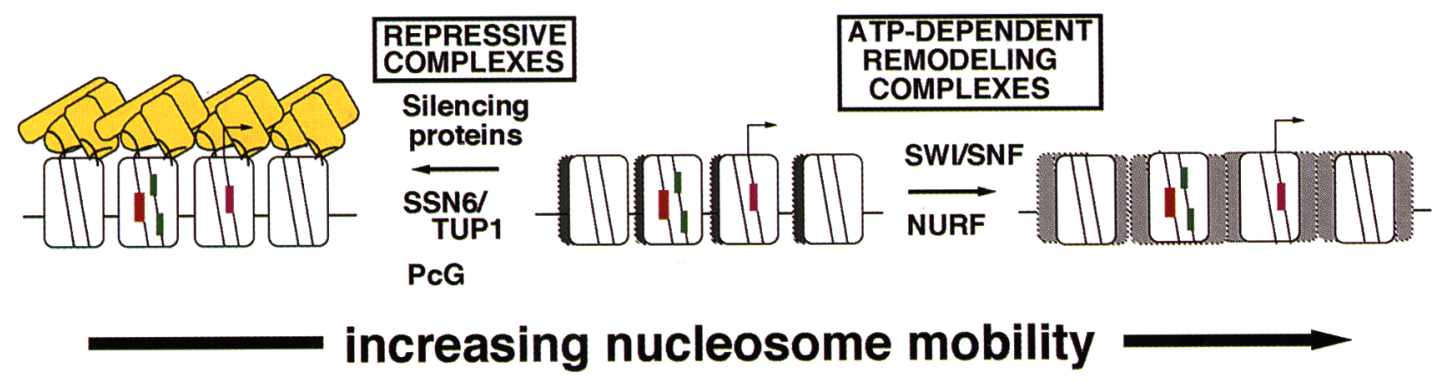

Figure 3. Nucleosome mobility as a key determinant of promoter activity. Multiprotein complexes might either increase or decrease nucleosome mobility to facilitate or inhibit transcription factor interaction (based on Meerseman et al. 1992; Hecht et al. 1995; Ura et al. 1995; Varga-Weisz et al. 1995). 
is in linker regions, or is on an adjacent nucleosome. DNA cross-linking studies have been used in several instances to assign specific contacts for the various amino termini of the core histones (Pruss et al. 1995). Specific mutations in amino termini have effects on activation, silencing, and repression by SSN6/TUP1 (see above). Amino termini can be acetylated on lysine residues, causing a decrease in their positive surface charge, and presumably affecting their binding to DNA. Hypoacetylation has been strongly correlated with inactive genes in yeast and in multicellular organisms (Braunstein et al. 1993; Jeppesen and Turner 1993), whereas hyperacetylation is associated with active genes (although in this latter case the correlation is not complete) (Hebbes et al. 1988; Bresnick et al. 1991; Bone et al. 1994).

These data suggest an important role for amino termini in modulating nucleosome-DNA interactions and thereby modulating the repressive effects that nucleosomes have on transcription factor interactions. In fact, deletion of amino termini has been shown to increase binding of TFIIIA and GAL4 to nucleosome cores, and hyperacetylation has also been reported to increase binding of TFIIIA (Lee et al. 1993; Vettese-Dadey et al. 1994). As discussed above, the amino terminus of histone $\mathrm{H} 4$ has been shown to contact SIR3, perhaps nucleating formation of a repressive complex. Biophysical analysis demonstrates an important role for amino termini in the structuring of nucleosomal arrays, as judged from the effects of acetylation or removal of amino termini on the supercoiling of circular templates and sedimentation (Norton et al. 1989; Fletcher and Hansen 1995). It is clear from this body of work that further structural and biophysical studies on the function of amino-terminal tails are required for a full understanding of how factors interact with nucleosomes and how regulatory complexes might alter chromatin structure.

\section{Nucleosome-associated proteins}

Acidic proteins, such as nucleoplasmin in frogs and NAP-1 in yeast, are capable of binding histones and thereby facilitating removal of nucleosomes from DNA. These proteins have been shown to increase binding of factors such as GAL4, USF, and Sp1 and will increase dissociation of histones from a nucleosome that has been bound by an activator (Chen et al. 1994; Walter et al. 1995). These factors may well work in conjunction with remodeling activities to help increase factor binding and perhaps to complete the formation of an open chromatin state by removing core histones from active regions.

\section{Nucleosome positioning}

Both repressed and activated promoters frequently contain nucleosomes that are confined to a discrete position or a set of positions (Richard-Foy and Hager 1987; Thomas and Elgin 1988; Wolffe and Brown 1988; Fragoso et al. 1995). Positioning has been proposed to repress expression by placing regulatory sites in an inaccessible place on the nucleosome and has been proposed to enhance expression by juxtaposing activator binding sites (for review, see Lu et al. 1994). The DNA sequences that determine positioning in natural promoters are not well understood, although there is a clear bias toward AT-rich sequences in the minor groove adjacent to the core region and GC-rich sequences facing away from the core. Sequence-specific binding proteins almost certainly can contribute to positioning. Recapitulation of appropriate positioning in vitro will be essential to understanding how nucleosomes might be repositioned by regulatory complexes and to understand whether repressive complexes stabilize positioning.

\section{Linker histones and higher order structures}

The nucleosome is the primary mode of packaging in chromatin; binding of linker histones (i.e., histones $\mathrm{Hl}$ and $\mathrm{H} 5$ |, formation of the $30-\mathrm{nm}$ fiber, and formation of higher order structures are also essential components of chromatin structure. Histone $\mathrm{Hl}$ is not found in yeast, so its role in establishing repressed complexes is not yet clear; specific repressive complexes are not yet characterized in multicellular eukaryotes that contain $\mathrm{H1}$. The effect of $\mathrm{Hl}$ on ATP-dependent remodeling in Drosophila extracts has been examined (Tsukiyama et al. 1994; Varga-Weisz et al. 1995). H1 decreases, but does not eliminate, the ATP-dependent stimulation of GAGA factor binding and the ATP-dependent stimulation of restriction enzyme access. These data suggest that $\mathrm{H} 1$ inhibits function of these remodeling activities, although it is possible that the remodeling activities are fully active and $\mathrm{H} 1$ directly interferes with factor access. Addition of histone $\mathrm{H} 5$ has been shown to decrease nucleosome mobility and repress RNA polymerase III transcription (Ura et al. 1995), providing a possible mechanism for repression of RNA polymerase II transcription by $\mathrm{Hl}$ (Kamakaka et al. 1993). In theory, formation of chromatin structures even more compacted than those formed with nucleosomes and $\mathrm{H} 1$ should severely restrict factor access and remodeling activities. This has not been addressed.

\section{Summary and perspectives}

Recent studies have provided strong evidence that macromolecular complexes are used in the cell to remodel chromatin structure during activation and to create an inaccessible structure during repression. Although there is not yet any rigorous demonstration that modification of chromatin structure plays a direct, causal role in either activation or repression, there is sufficient smoke to indicate the presence of a blazing inferno nearby. It is clear that complexes that remodel chromatin are tractable in vitro; hopefully this will allow the establishment of systems that provide a direct analysis of the role that remodeling might play in activation. These studies indicate that establishment of functional systems to corroborate the elegant genetic studies on repression might also be tractable. As the mechanistic effects of these complexes are sorted out, it will become important to 
understand how the complexes are regulated. In many of the instances discussed above, the genes whose products make up these complexes were identified in genetic screens for effects on developmental processes. This implies a regulation of the activity of these complexes in response to developmental cues and further implies that the work to fully understand these complexes will occupy a generation of scientists.

\section{Acknowledgments}

We thank W. Bender, S. Brown, D. Gross, M. Grunstein, C. Peterson, M. Ptashne, F. Winston, and J. Workman for helpful comments. Work in our laboratory was supported by grants from the National Institutes of Health and Hoechst AG.

\section{References}

Adams, C.C. and J.L. Workman. 1993. Nucleosome displacement in transcription. Cell 72: 305-308.

Aparicio, O.M. and D.E. Gottschling. 1994. Overcoming telomeric silencing: A trans-activator competes to establish gene expression in a cell cycle-dependent way. Genes \& Dev. 8: 1133-1146.

Aparicio, O.M., B.L. Billington, and D.E. Gottschling. 1991. Modifiers of position effect are shared between telomeric and silent mating-type loci in S. cerevisiae. Cell 66: 12791287.

Arents, G. and E.N. Moudrianakis. 1993. Topography of the histone octamer surface: Repeating structural motifs utilized in the docking of nucleosomal DNA. Proc. Natl. Acad. Sci. 90: 10489-10493.

Arents, G., R.W. Burlingame, B.-C. Wang, W.E. Love, and E.N. Moudrianakis. 1991. The nucleosome core histone octamer at 3.1 A resolution: A tripartite protein assembly and a lefthanded superhelix. Proc. Natl. Acad. Sci. 88: 10148-10152.

Axelrod, J.D., M.S. Reagan, and J. Majors. 1993. GAL4 disrupts a repressing nucleosome during activation of GAL1 transcription in vivo. Genes \& Dev. 7: 857-869.

Barberis, A., J. Pearlberg, N. Simkovich, S. Farrell, P. Reinagel, C. Bamdad, G. Sigal, and M. Ptashne. 1995. Contact with a component of the polymerase II holoenzyme suffices for gene activation. Cell 81: 359-368.

Becker, P.B. 1994. The establishment of active promoters in chromatin. BioEssays 16: 541-547.

Becker, P.B. and C. Wu. 1992. Cell-free system for assembly of transcriptionally repressed chromatin from Drosophila embryos. Mol. Cell. Biol. 12: 2241-2249.

Bone, J.R., J. Lavender, R. Richman, M.J. Palmer, B.M. Turner, and M.I. Kuroda. 1994. Acetylated histone H4 on the male X chromosome is associated with dosage compensation in Drosophila. Genes \& Dev. 8: 96-104.

Braunstein, M., A.B. Rose, S.G. Holmes, C.D. Allis, and J.R. Broach. 1993. Transcripional silencing in yeast is associated with reduced nucleosome acetylation. Genes \& Dev. 7: 592 604.

Breeden, L. and K. Nasmyth. 1987. Cell cycle control of the yeast HO gene: cis- and trans-acting regulators. Cell 48: 389-397.

Brent, R. 1986. How to run a very small factory. Cell 47:329330.

Bresnick, E.H., M. Bustin, V. Marsaud, H. Richard-Foy, and G.L. Hager. 1991. The transcriptionally-active MMTV promoter is depleted of histone H1. Nucleic Acids Res. 20(2): 273-278.
Bunker, C.A. and R.E. Kingston. 1994. Transcriptional repression by Drosophila and mammalian Polycomb group proteins in transfected mammalian cells. Mol. Cell. Biol. 14: 1721-1732.

Busturia, A. and M. Bienz. 1993. Silencers in Abdominal-B a homeotic Drosophila gene. EMBO J. 12: 1415-1425.

Cairns, B.R., Y.-J. Kim, M.H. Sayre, B.C. Laurent, and R.D. Kornberg. 1994. A multisubunit complex containing the SWI1/ ADR6, SWI2/SNF2, SWI3, SNF5, and SNF6 gene products isolated from yeast. Proc. Natl. Acad. Sci. 91: 1950-1954.

Cavalli, G. and F. Thoma. 1993. Chromatin transitions during activation and repression of galactose-regulated genes in yeast. $E M B O$ I. 12(12): 4603-4613.

Chan, C.-S., L. Rastelli, and V. Pirrotta. 1994. A Polycomb response element in the $U b x$ gene that determines an epigenetically inherited state of repression. EMBO I. 13: 25532564.

Chen, H., B. Li, and J.L. Workman. 1994. A histone-binding protein, nucleoplasmin, stimulates transcription factor binding to nucleosomes and factor-induced nucleosome disassembly. EMBO I. 13(2): 380-390.

Chiang, A., M.B. O'Connor, R. Paro, J. Simon, and W. Bender. 1995. Discrete Polycomb-binding sites in each parasegmental domain of the bithorax complex. Development 121: $1681-1689$.

Chiba, H., M. Muramatsu, A. Nomoto, and H. Kato. 1994. Two human homologues of Saccharomyces cerevisiae SWI2/ SNF2 and Drosophila Brahma are transcriptional coactivators cooperating with the estrogen receptor and the retinoic acid receptor. Nucleic Acids Res. 22(10): 1815-1820.

Chien, C., S. Buck, R. Sternglanz, and S. Shore. 1993. Targeting of SIRI protein establishes transcriptional silencing at HM loci and telomeres in yeast. Cell 75: 531-541.

Cooper, J.P., S.Y. Roth, and R.T. Simpson. 1994. The global transcriptional regulators, SSN6 and TUP1, play distinct roles in the establishment of a repressive chromatin structure. Genes \& Dev. 8: 1400-1410.

Côté, J., J. Quinn, J.L. Workman, and C.L. Peterson. 1994. Stimulation of GAL4 derivative binding to nucleosomal DNA by the yeast SWI/SNF complex. Science 265: 53-60.

Crosten, G.E., L.E. Kerrigan, L.M. Lira, D.R. Marshak, and J.T. Kadonaga. 1991. Sequence specific anti-repression of histone H1 mediated inhibition of basal RNA polymerase II transcription. Science 251: 643-649.

DeCamillis, M., N. Cheng, D. Pierre, and H.W. Brock. 1992. The polyhomeotic gene of Drosophila encodes a chromatin protein that shares polytene chromosome-binding sites with Polycomb. Genes \& Dev. 6: 223-232.

Dunaief, J.L., B.E. Strober, S. Guha, P.A. Khavari, K. Ålin, J. Luban, M. Begemann, G.R. Crabtree, and S.P. Goff. 1994. The retinoblastoma protein and BRGI form a complex and cooperate to induce cell cycle arrest. Cell 79: 119-130.

Durrin, L.K., R.K. Mann, P.S. Kayne, and M. Grunstein. 1991. Yeast histone $\mathrm{H} 4 \mathrm{~N}$-terminal sequence is required for promoter activation in vivo. Cell 65: 1023-1031.

Elfring, L.K., R. Deuring, C.M. McCallum, C.L. Peterson, and J.W. Tamkun. 1994. Identification and characterization of Drosophila relatives of the yeast transcriptional activator SNF2/SWI2. Mol. Cell. Biol. 14(4): 2225-2234.

Emili, A. and C.J. Ingles. 1995. The RNA polymerase II carboxyterminal domains: Links to a bigger and better "holoenzyme"'? Curr. Opin. Genet. Dev. 5: 204-209.

Felsenfeld, G. 1992. Chromatin as an essential part of transcriptional mechanism. Nature 355: 219-224.

Fletcher, T.M. and J.C. Hansen. 1995. Core histone tail domains mediate oligonucleosome folding and nucleosomal DNA or- 
ganization through distinct molecular mechanisms. /. Biol. Chem. 270: 25359-25362.

Fox, C.A., S. Loo, A. Dillin, and J. Rine. 1995. The origin replication complex has essential functions in transcriptional silencing and chromosomal replication. Genes \& Dev. 9: 911924.

Fragoso, G., S. John, M.S. Roberts, and G.L. Hager. 1995. Nucleosome positioning on the MMTV LTR results from the frequency-biased occupancy of multiple frames. Genes \& Dev. 9: 1933-1947.

Franke, A., M. DeCamillis, D. Zink, N. Cheng, H.W. Brock, and R. Paro. 1992. Polycomb and polyhomeotic are constituents of a multimeric protein complex in chromatin of Drosophila melanogaster. $E M B O$ J. 11(8): 2941-2950.

Geise, K., J. Cox, and R. Grosschedl. 1992. The HMG domain of lymphoid enhancer factor 1 bends DNA and facilitates assembly of functional nucleoprotein structures. Cell 69: 185195.

Gindhart, J.G. and T.C. Kaufman. 1995. Identification of Polycomb and trithorax group responsive elements in the regulatory regions of the Drosophila homeotic gene Sex combs reduced. Genetics 139: 797-814.

Gottschling, D.E. 1992. Telomere-proximal DNA in Saccharomyces cerevisiae is refractory to methyltransferase activity in vivo. Proc. Natl. Acad. Sci. 89: 4062-4065.

Gottschling, D.E., O.M. Aparicio, B.L. Billington, and V.A. Zakian. 1990. Position effect at $S$. cerevisiae telomeres: Reversible repression of Pol II transcription. Cell 63: 751-762.

Grigliatti, T. 1991. Position-effect variegation-An assay for nonhistone chromosomal proteins and chromatin assembly and modifying factors. Methods Cell Biol. 35: 587-627.

Gross, D.S. and W.T. Garrard. 1988. Nuclease hypersensitive sites in chromatin. Annu. Rev. BioChem. 57: 159-197.

Happel, A.M., M.S. Swanson, and F. Winston. 1991. The SNF2, SNF5, and SNF6 genes are required for Ty transcription in Saccharomyces cerevisiae. Genetics 128: 69-77.

Haupt, Y., W.S. Alexancier, G. Barri, S.P. Klinken, and J.M. Adams. 1991. Novel zinc finger gene implicated as myc collaborator by retrovirally accelerated lymphomagenesis in $\mathrm{Em}$ myc transgeneic mice. Cell 65: 753-763.

Hebbes, T.R., A.W. Thorne, and C. Crane-Robinson. 1988. A direct link between core histone acetylation and transcriptionally active chromatin. EMBO I. 7: 1395-1402.

Hecht, A., T. Laroche, S. Strahl-Bolsinger, S.M. Gasser, and M. Grunstein. 1995. Histone $\mathrm{H} 3$ and $\mathrm{H} 4 \mathrm{~N}$-termini interact with SIR3 and SIR4 proteins: A molecular model for the formation of heterochromatin in yeast. Cell 80: 583-592.

Herschbach, B.M., M.B. Arnaud, and A.D. Johnson. 1994. Transcriptional repression directed by the yeast $\alpha 2$ protein in vitro. Nature 370: 309-311.

Hirschhorn, J.N., S.A. Brown, C.D. Clark, and F. Winston. 1992. Evidence that SNF2/SWI2 and SNF5 activate transcription in yeast by altering chromatin structure. Genes \& Dev. 6: $2288-2298$.

Hirschhorn, J.N., A.L. Bortvin, S.L. Ricupero-Hovasse, and F. Winston. 1995. A new class of histone H2A mutations in Saccharomyces cerevisiae causes specific transcriptional defects in vivo. Mol. Cell. Biol. 15: 1999-2009.

Imbalzano, A.N., H. Kwon, M.R. Green, and R.E. Kingston. 1994. Facilitated binding of TATA-binding protein to nucleosomal DNA. Nature 370: 481-485.

Ingham, P.W. 1983. Differential expression of bithorax complex genes in the absence of the extra sex combs and trithorax genes. Nature 306: 591-593.

Izban, M.G. and D.S. Luse. 1992. Factor-stimulated RNA polymerase II transcribes at physiological elongation rates on naked DNA but very poorly on chromatin templates. I. Biol. Chem. 267(19): 13647-13655.

Jeppesen, P. and B.M. Turner. 1993. The inactive X chromosome in female mammals is distinguished by a lack of histone $\mathrm{H} 4$ acetylation, a cytogenetic marker for gene expression. Cell 74: 281-289.

Johnson, A.D. 1995. The price of repression. Cell 81: 655-658.

Kalpana, G.V., S. Marmon, W. Wang, G.R. Crabtree, and S.P. Goff. 1994. Binding and stimulation of HIV-1 integrase by a human homolog of yeast transcription factor SNF5. Science 266: 2002-2006.

Kamakaka, R.T., M. Bulger, and J.T. Kadonaga. 1993. Potentiation of RNA polymerase II transcription by Gal4-VP16 during but not after DNA replication and chromatin assembly. Genes \& Dev. 7: 1779-1795.

Kayne, P.S., U.-J. Kim, M. Han, J.R. Mullen, F. Yoshizaki, and M. Grunstein. 1988. Extremely conserved histone H4 N terminus is dispensible for growth but essential for repressing the silent mating loci in yeast. Cell 55: 27-39.

Kennison, J.A. and J.W. Tamkun. 1988. Dosage-dependent modifiers of Polycomb and Antennapedia mutations in Drosophila. Proc. Natl. Acad. Sci. 85: 8136-8140.

Khavari, P.A., C.L. Peterson, J.W. Tamkun, and G.R. Crabtree. 1993. BRG l contains a conserved domain of the SWI2/SNF2 family necessary for normal mitotic growth and transcription. Nature 366: 170-174.

Kim, Y.-I., S. Björklund, Y. Li, M.H. Sayre, and R.D. Kornberg 1994. A multiprotein mediator of transcriptional activation and its interaction with the C-terminal repeat domain of RNA polymerase II. Cell 77: 599-608.

Koleske, A.J. and R.A. Young. 1994. An RNA polymerase II holoenzyme responsive to activators. Nature 368: 466-469.

Kruger, W. and I. Herskowitz. 1991. A negative regulator of HO transcription, SIN1 (SPT2), is a nonspecific DNA binding protein related to HMG I. Mol. Cell. Biol. 11: 4135-4146.

Kruger, W., C.L. Peterson, A. Sil, C. Coburn, G. Arents, E.N. Moudrianakis, and I. Herskowitz. 1995. Amino acid substitutions in the structured domains of histones $\mathrm{H} 3$ and $\mathrm{H} 4$ partially relieve the requirement of the yeast SWI/SNF complex for transcription. Genes \& Dev. 9: 2770-2779.

Kwon, H., A.N. Imbalzano, P.A. Khavari, R.E. Kingston, and M.R. Green. 1994. Nucleosome disruption and enhancement of activator binding by a human SWI/SNF complex. Nature 370: 477-481.

Laurenson, P. and J. Rine. 1992. Silencers, silencing, and heritable transcriptional states. Microbiol. Rev. 56: 543-560.

Laurent, B.C. and M. Carlson. 1992. Yeast SNF2/SWI2, SNF5, and SNF6 proteins function coordinately with the gene-specific transcriptional activators GAL4 and Bicoid. Genes \& Dev. 6: $1707-1715$

Laurent, B.C., M.A. Treitel, and M. Carlson. 1991. Functional interdependence of the yeast SNF2, SNF5, and SNF6 proteins in transcriptional activation. Proc. Natl. Acad. Sci. 88: 2687-2691.

Laurent, B.C., I. Treich, and M. Carlson. 1993. The yeast SNF2/ SWI2 protein has DNA-stimulated ATPase activity required for transcriptional activation. Genes \& Dev. 7: 583-591.

Lee, D.Y., J.J. Hayes, D. Pruss, and A.P. Wolffe. 1993. A positive role for histone acetylation in transcription factor access to nucleosomal DNA. Cell 72: 73-84.

Lewis, E.B. 1978. A gene complex controlling segmentation in Drosophila. Nature 276: 565-570.

Lis, J. and C. Wu. 1993. Protein traffic onthe heat shock promoter: Parking, stalling and trucking along. Cell 74: 1-4.

Lonie, A., R. D'Andrea, R. Paro, and R. Saint. 1994. Molecular characterisation of the Polycomblike gene of Drosophila 
melanogaster a trans-acting negative regulator of homeotic gene expression. Development 120: 2629-2636.

Loo, S. and J. Rine. 1994. Silencers and domains of generalized repression. Science 264: 1768-1771.

Lorch, Y., J.W. LaPointe, and R.D. Kornberg. 1987. Nucleosomes inhibit the initiation of transcription but allow chain elongation with the displacement of histones. Cell 49: 203210.

Lorch, Y., J.W. LaPointe, and R.D. Kornberg. 1992. Initiation on chromatin templates in a yeast RNA polymerase II transcription system. Genes \& Dev. 6: 2282-2287.

Lu, Q., L.L. Wallrath, and S.C.R. Elgin. 1994. Nucleosome positioning and gene regulation. I. Cell. Biochem. 55: 83-92.

Matallana, E., L. Franco, and J.E. Perez-Ortin. 1992. Chromatin structure of the yeast SUC2 promoter in regulatory mutants. Mol. \& Gen. Genet. 231: 395-400.

McCall, K. and W. Bender 1996. Probes for chromatin accessibility in the Drosophila bithorax complex respond differently to Polycomb-mediated repression. EMBO I. 15: 569580.

Meersseman, G., S. Pennings, and E.M. Bardbury. 1992. Mobile nucleosomes-A general behavior. EMBO I. 11(8): 29512959.

Moretti, P., K. Freeman, L. Coodly, and D. Shore. 1994. Evidence that a complex of SIR proteins interacts with the silencer and telomere-binding protein RAP1. Genes \& Dev. 8: 2257-2269.

Muchardt, C. and M. Yaniv. 1993. A human homologue of Saccharomyces cerevisiae SNF2/SWI2 and Drosophila brm genes potentiates transcriptional activation by the glucocorticoid receptor. EMBO I. 12: 4279-4290.

Müller, J. 1995. Transcriptional silencing by the Polycomb protein in Drosophila embryos. EMBO /. 14(6): 1209-1220.

Neigeborn, L. and M. Carlson. 1984. Genes affecting the regulation of SUC2 gene expression by glucose repression in SaCcharomyces cerevisiae. Genetics 108: 845-858.

Newlon, C.S. 1993. Two jobs for the origin replication complex. Science 262: 1830-1831.

Norton, V.G., B.S. Imai, P. Yau, and E.M. Bradbury. 1989. Histone acetylation reduces nucleosome core particle linking number change. Cell 57: 449-457.

Okabe, I., L.C. Bailey, O. Attree, S. Srinivasan, J.M. Perkel, B.C. Laurent, M. Carlson, D.L. Nelson, and R.L. Nussbaum. 1992. Cloning of human and bovine homologs of SNF2/ SWI2 a global activator of transcription in yeast $S$. cerevisiae. Nucleic Acids Res. 20(17): 4649-4655.

Orlando, V. and R. Paro. 1993. Mapping polycomb-repressed domains in the bithorax complex using in vivo formaldehyde cross-linked chromatin. Cell 75: 1187-1198.

. 1995. Chromatin multiprotein complexes involved in the maintenance of transcription patterns. Curr. Opin. Genet. Dev. 5: 174-179.

Palladino, F. and S.M. Gasser. 1994. Telomere maintenance and gene repression: A common end? Curr. Opin. Cell Biol. 6: 373-379.

Palladino, F., T. Laroche, E. Gilson, A. Axelrod, L. Pillus, and S.M. Gasser. 1993. SIR3 and SIR4 proteins are required for the positioning and integrity of yeast telomeres. Cell 75: 543-555.

Paranjape, S.M., R.T. Kamakaka, and I.T. Kadonaga. 1994. Role of chromatin structure in the regulation of transcription by RNA polymerase II. Annu. Rev. BioChem. 63: 265-297.

Paro, R. 1990. Imprinting a determined state into the chromatin of Drosophila. Trends Genet. 6(12): 416-421.

. 1995. Propagating memory of transcriptional states. Trends Genet. 11: 295-297.
Paro, R. and D.S. Hogness. 1991. The Polycomb protein shares a homologous domain with a heterochromatin-associated protein of Drosophila. Proc. Natl. Acad. Sci. 88: 263-267.

Pazin, M.J., R.T. Kamakaka, and J.T. Kadonaga. 1994. ATP-dependent nucleosome reconfiguration and transcriptional activation from preassembled chromatin templates. Science 266: 2007-2011

Peterson, C.L., W. Kruger, and I. Hershowitz. 1991. A functional interaction between the C-terminal domain of RNA polymerase II and the negative regulator SIN1. Cell 64: 11351143.

Peterson, C.L., A. Dingwall, and M.P. Scott. 1994. Five SWI/ $S N F$ gene products are components of a large multiprotein complex required for transcriptional enhancement. Proc. Natl. Acad. Sci. 91: 2905-2908.

Peterson, L. and I. Herskowitz. 1992. Characterization of the yeast SWI1, SWI2, and SWI3 genes, which encode a global activator of transcription. Cell 68: 573-583.

Pruss, D., J.J. Hayes, and A.P. Wolffe. 1995. Nucleosomal anatomy-where are the histones? BioEssays 17(2): 161-170.

Quinn, J., A.M. Fyrberg, R.W. Ganster, M.C. Schmidt, and C.L. Peterson. 1996. The yeast SWI/SNF complex has DNA-binding properties similar to HMG-box proteins. Nature 379: 844-847.

Rastelli, L., C.S. Chan, and V. Pirrotta. 1993. Related chromosome binding sites for zeste, suppressors of zeste and Polycomb group proteins in Drosophila and their dependence on Enhancer of zeste function. EMBO /. 12(4): 1513-1522.

Renauld, H., O.M. Aparicio, P.D. Zierath, B.L. Billington, S.K. Chhablani, and D.E. Gottschling. 1993. Silent domains are assembled continuously from the telomere and are defined by promoter distance and strength, and by SIR3 dosage. Genes \& Dev. 7: 1133-1145.

Richard-Foy, H. and G.L. Hager. 1987. Sequence-specific positioning of nucleosomes over the steroid-inducible MMTV promoter. EMBO I. 6: 2321-2328.

Richmond, T.J., J.T. Finch, D. Rhodes, and A. Klug. 1984. Structure of the nucleosome core particle at $7 \mathrm{~A}$ resolution. $\mathrm{Na}$ ture 311: 532-537.

Rine, I. and I. Herskowitz. 1987. Four genes responsible for a position effect on expression from $H M L$ and $H M R$ in Saccharomyces cerevisiae. Genetics 116: 9-22.

Roth, S.Y. 1995. Chromatin-mediated transcriptional repression in yeast. Curr. Opin. Genet. Dev. 5: 168-173.

Roth, S.Y., A. Dean, and R.T. Simpson. 1990. Yeast $\alpha 2$ repressor positions nucleosomes in TRP1/ARS l chromatin. Mol. Cell. Biol. 10(5): 2247-2260.

Roth, S.Y., M. Shimizu, L. Johnson, and M. Grunstein. 1992. Stable nucleosome positioning and complete repression by the yeast $\alpha 2$ repressor are disrupted by amino-terminal mutations in histone H4. Genes \& Dev. 6: 411-425.

Schmid, A., K.-D. Fascher, and W. Horz. 1992. Nucleosome disruption at the yeast $\mathrm{PHO}$ promoter upon $\mathrm{PHO} 5$ induction occurs in the absence of DNA replication. Cell 71: 853-864.

Sheridan, P.L., C.T. Sheline, K. Cannon, M.L. Voz, M.J. Pazin, J.T. Kadonaga, and K.A. Jones. 1995. Activation of the HIV-1 enhancer by the LEF-1 HMG protein on nucleosome-assembled DNA in vitro. Genes \& Dev. 9: 2090-2104.

Shimizu, M., S.Y. Roth, C. Szent-Gyorgyi, and R.T. Simpson. 1991. Nucleosomes are positioned with base pair precision adjacent to the $\alpha 2$ operator in Saccharomyces cerevisiae. $E M B O$ /. 10(10): 3033-3041.

Shore, D. 1994. RAPl: A protean regulator in yeast. Trends Genet. 10: 408-412.

Shore, D. and K. Nasmyth. 1987. Purification and cloning of a DNA binding protein from yeast that binds to both silencers 
and activator elements. Cell 51: 721-732.

Simon, J. 1995. Locking in stable states of gene expression: transcriptional control during Drosophila development. Curr. Opin. Cell Biol. 7: 376-385.

Simon, J., A. Chiang, W. Bender, M.J. Shimell, and M. O'Connor. 1993. Elements of the Drosophila bithorax complex that mediate repression by Polycomb group products. Dev. Biol. 158: $131-144$.

Singh, P., J. Coe, and W. Hong. 1995. A role for retinoblastoma protein in potentiating transcriptional activation by the glucocorticoid receptor. Nature 374: 562-565.

Stern, M.J., R. Jensen, and I. Herskowitz. 1984. Five SWI genes are required for expression of the $\mathrm{HO}$ gene in yeast. I. Mol. Biol. 178: 853-868.

Sternberg, P.W., M.J. Stern, I. Clark, and I. Herskowitz. 1987. Activation of the yeast $H O$ gene by release from multiple negative controls. Cell 48: 567-577.

Strober, B.E., J.L. Dunaief, S. Guha, and S.P. Goff. 1996. Functional interactions between the hBRM/hBRGl transcriptional activators and the pRB family of proteins. Mol. Cell. Biol. 16: (in press).

Struhl, G. 1981. A gene product required for correct initiation of senmental determination in Drosophila. Nature 293: 36-41.

Studitsky, V.M., D.J. Clark, and G. Felsenfeld. 1994. A histone octamer can step around a transcribing polymerase without leaving the template. Cell 76: 371-382.

- 1995. Overcoming a nucleosomal barrier to transcription. Cell 83: 19-27.

Tamkun, J.W., R. Deuring, M.P. Scott, M. Kissinger, A.M. Pattatucci, T.C. Kaufman, and J.A. Kennison. 1992. brahma: A regulator of Drosophila homeotic genes structurally related to the yeast transcription activator SNF2/SWI2. Cell 68: $561-572$.

Thomas, G.H. and S.C.R. Elgin. 1988. Protein/DNA architecture of the DNase I hypersensitive region of the Drodophila HSP26 promoter. EMBO I. 7: 2191-2201.

Treich, I., B.R. Cairns, T. de los Santos, E. Brewster, and M. Carlson. 1995. SNF11, a new component of the yeast SNF/ SWI complex that interacts with a conserved region of SNF2. Mol. Cell. Biol. 15: 4240-4248.

Tsukiyama, T. and C. Wu. 1995. Purification and properties of an ATP-dependent nucleosome remodeling factor. Cell 83: $1011-1020$.

Tsukiyama, T., P.B. Becker, and C. Wu. 1994. ATP-dependent nuclesome disruption at a heat-shock promoter mediated by binding of GAGA transcription factor. Nature 367: 525-531.

Tsukiyama, T., C. Daniel, J. Tamkun, and C. Wu. 1995. ISWI, a member of the SWI2/SNF2 ATPase family, encodes the 140 $\mathrm{kDa}$ subunit of the nucleosome remodeling factor. Cell 83: 1021-1026.

Tzamarias, D. and K. Struhl. 1994. Functional dissection of the yeast Cyc8-Tupl transcriptional co-repressor complex. $\mathrm{Na}$ ture 369: 758-761.

Ura, K., J.J. Hayes, and A.P. Wolffe. 1995. A positive role for nucleosome mobility in the transcriptional activity of chromatin templates: restriction by linker histones. EMBO \% 14: 3752-3765.

van Lohuizen, M., M. Frasch, E. Wientjens, and A. Berns. 1991 a. Sequence similarity between the mammalian bmi-1 protooncogene and the Drosophila regulatory genes $P S C$ and Su(z)2. Nature 353: 353-355.

van Lohuizen, M., S. Verbeek, B. Scheijen, E. Wientiens, H. van der Gulden, and A. Berns. 1991b. Identification of cooperating oncogenes in Em-myc transgenic mice by provirus tag. ging. Cell 65: 737-752.

Varga-Weisz, P.D., T.A. Blank, and P.B. Becker. 1995. Energy- dependent chromatin accessibility and nucleosome mobility in a cell-free system. EMBO /. 14(10): 2209-2216.

Vettese-Dadey, M., P. Walter, H. Chen, L.-J. Juan, and J.L. Workman. 1994. Role of the histone amino termini in facilitated binding of a transcription factor, GAL4-AH, to nucleosome cores. Mol. Cell. Biol. 14(2): 970-981.

Wall, G., P.D. Varga-Weisz, R. Sandaltzopoulos, and P.B. Becker. 1995. Chromatin remodeling by GAGA factor and heat shock factor at the hypersensitive Drosophila hsp26 promoter in vitro. EMBO I. 14: 1727-1736.

Walter, P.P., T.A. Owen-Hughes, J. Côté, and J.L. Workman. 1995. Stimulation of transcription factor binding and histone displacement by nucleosome assembly protein $l$ and nucleoplasmin requires disruption of the histone octamer. Mol. Cell. Biol. 15(11): 6178-6187.

Williams, F.E., V. Varanasi, and R.J. Trumbly. 1991. The CYC8 and TUPl proteins involved in glucose repression in Saccharomyces cerevisiae are associated in a protein complex. Mol. Cell. Biol. 11(6): 3307-3316.

Wilson, C.J., D.M. Chao, A.N. Imbalzano, G.R. Schnitzler, R.E. Kingston, and R.A. Young. 1996. RNA polymerase II holoenzyme contains SWI/SNF regulators involved in chromatin remodeling. Cell 84: 235-244.

Winston, F. and M. Carlson. 1992. Yeast SNF/SWI transcriptional activators and the SPT/SIN chromatin connection. Trends Genet. 8: 387-391.

Wolffe, A.P. 1994. Transcription: In tune with histones. Cell 77: $13-16$

Wolffe, A.P. and D.D. Brown. 1988. Developmental regulation of two 5 S ribosomal RNA genes. Science 241: 1626-1632.

Workman, I.L., S.M. Abmayer, W.A. Cromlish, and R.G. Roeder. 1988. Transcriptional regulation by the immediate early protein of pseudorabies virus during in vitro nucleosome assembly. Cell 55: 211-219.

Workman, I.L., I.C.A. Taylor, and R.E. Kingston. 1991. Activation domains of stably bound GAL4 derivatives alleviate repression of promoters by nucleosomes. Cell 64: 533-544.

Wu, C. 1980 . The $5^{\prime}$ ends of Drosophila heat shock genes in chromatin are hypersensitive to DNase I. Nature 286: 854860.

Yoshinaga, S.K., C.L. Peterson, I. Herskowitz, and K.R. Yamamoto. 1992. Roles of SWI1, SWI2, and SWI3 proteins for transcriptional enhancement by steroid receptors. Science 258: $1598-1604$.

Zink, B. and R. Paro. 1989. In vivo binding pattern of a transregulator of homoeotic genes in Drosophila melanogaster. Nature 337: 468-471.

1995. Drosophila Polycomb-group regulated chromatin inhibits the accessibility of a trans-activator to its target DNA. EMBO I. 14(22): 5660-5671.

Zink, B., Y. Engstrom, W.J. Gehring, and R. Paro. 1991. Direct interaction of the Polycomb protein with Antennapedia regulatory sequences in polytene chromosomes of Drosophila melanogaster. EMBO /. 10(1): 153-162. 


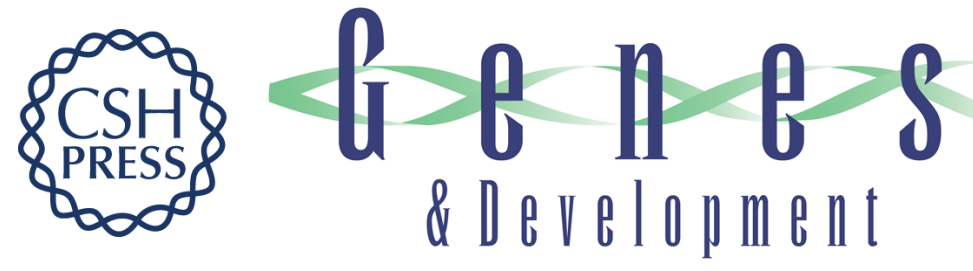

\section{Repression and activation by multiprotein complexes that alter chromatin structure.}

R E Kingston, C A Bunker and A N Imbalzano

Genes Dev. 1996, 10:

Access the most recent version at doi:10.1101/gad.10.8.905

References This article cites 147 articles, 53 of which can be accessed free at:

http://genesdev.cshlp.org/content/10/8/905.full.html\#ref-list-1

License

Email Alerting

Service

Receive free email alerts when new articles cite this article - sign up in the box at the top right corner of the article or click here.

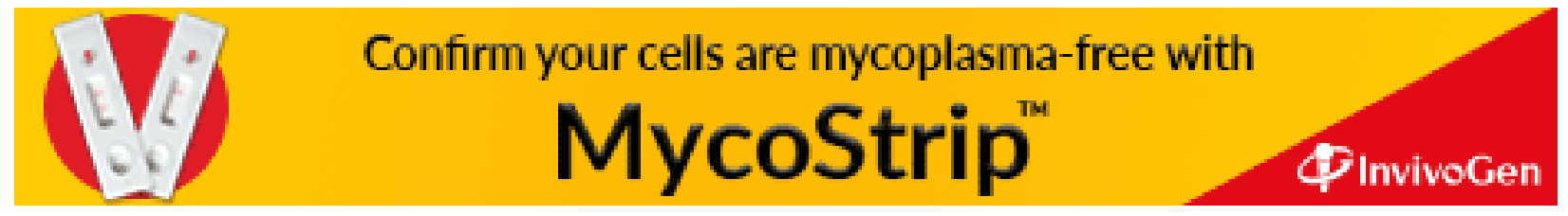

